\title{
The status and conservaltion of saproxylic beetles in Europe
}

\section{A. Nieto ${ }^{1}$, K.N.A. Alexander ${ }^{2}$}

i IUCN Regional Office for Pan Europe, 64, Boulevard Louis Schmidt, io4o Brussels, Belgium 2 59, Sweetbrier Lane, Heavitree, Exeter EXI 3 AQ, UK

\section{ABSTRACT}

The European Red List consists of a selection of 436 saproxylic beetles native to Europe or naturalised in Europe before AD 1500. Red List assessments were made at two regional levels: for geographical Europe and for the 27 Member States of the European Union.

Overall nearly $11 \%$ of the assessed saproxylic beetles are considered threatened in all Europe, while at the EU 27 level, 14\% are threatened. A further $13 \%$ of saproxylic beetles are considered Near Threatened. However, for more than a quarter $(28 \%)$ of the species, there were not enough scientific information to evaluate their risk of extinction and they were classified as Data Deficient.

Almost $14 \%$ of the species assessed have declining populations. Approximately $27 \%$ are thought to be more or less stable, and only $2 \%$ are increasing. The population trend for 249 species (57\%) remains unknown.

Saproxylic beetles in Europe are mainly threatened by habitat loss in relation to logging and wood harvesting and the decline of veteran trees throughout the landscape, as well as the lack of land management targeted at promotion of recruitment of new generations of trees.

It is hoped that the results of this Red List will stimulate research, monitoring and conservation action of saproxylic beetles at the local, regional and international levels.

\section{KEYWORDS}

saproxylic beetles, red list, conservation status, distribution, threats, Europe.

\section{INTRODUCTION}

The European Red List of saproxylic beetles is part of a wider initiative, the European Red List, that is a review of the conservation status of ca. 6.000 species (mammals, amphibians, reptiles, butterflies, dragonflies, saproxylic beetles, molluscs, freshwater fish and vascular plants) according to IUCN regional Red Listing guidelines. 
Given the importance that saproxylic beetle species play in decomposition processes and thus for recycling nutrients in natural ecosystems, it is important to identify those species that are threatened with extinction at the regional level - in order that appropriate conservation action can be taken to improve their status.

The European Red List of saproxylic beetles consists of a selection of 436 species. This study could not assess all European saproxylic beetles due to time and financial constraints, but combined full coverage of selected families and subfamilies, together with a small number of individual species.

This is the first Red List assessment of an ecological grouping at the European level and it has proven to provide unusual conservation perspectives and insights on the needs of saproxylic organisms and, in particular, on the need to properly consider their requirements when managing protected areas and natural resources in the wider landscapes.

\section{OBJECTIVES OF THE ASSESSMENT}

The European regional assessment has four main objectives:

- To contribute to regional conservation planning through provision of a baseline dataset reporting the status of European saproxylic beetles

- To identify those geographic areas and habitats needing to be conserved to prevent extinctions and to ensure that European saproxylic beetles reach and maintain a favourable conservation status

- To identify the major threats and to propose mitigating measures and conservation actions to address them

- To strengthen the network of experts focused on saproxylic beetles conservation in Europe, so that the assessment information can be kept current, and expertise can be targeted to address the highest conservation priorities.

\section{THE IUCN RED LIST: A KEY CONSERVATION TOOL}

The threatened status of plants and animals is one of the most widely used indicators for assessing the condition of ecosystems and their biodiversity. It also provides an important tool underpinning priority-setting exercises for species conservation. At the global scale the best source of information on the conservation status of plants and animals is the IUCN Red List of Threatened Species (see www. iucnredlist.org; IUCN 2009). The Red List provides taxonomy, conservation status, distribution, main threats and conservation measures on taxa that have been evaluated using the IUCN Red List Categories and Criteria: Version 3.1 (IUCN 2001). This system is designed to determine the relative risk of extinction, with the main purpose of cataloguing and highlighting those taxa that are facing a higher risk of extinction. The Categories are based on a set of quantitative criteria linked to population trends, population size and structure and geographic range. Species that have been classified as Critically Endangered, Endangered and Vulnerable are considered as 'threatened' (Fig. 1). The IUCN Red List is intended to be policy relevant, and it can be used to inform conservation planning and priority setting processes, but it is not intended to be policy prescriptive, and it is not in and of itself a biodiversity conservation priority-setting system.

Figure 1. IUCN Red List Categories at regional scale

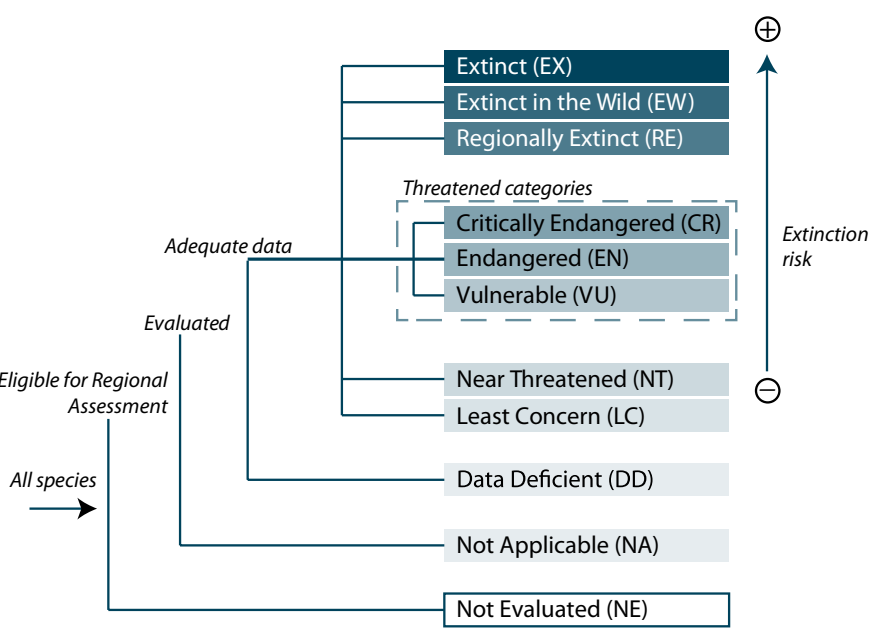




\section{GEOGRAPHIC SCOPE}

The geographical scope is continent-wide, extending from Iceland in the west to the Urals in the east (including European parts of the Russian Federation), and from Franz Josef Land in the north to the Mediterranean in the south. The Canary Islands, Madeira and the Azores were also included. In the southeast, where definitions of Europe are more contentious, the Caucasus region was not included.

Red List assessments were made at two regional levels: 1) for geographical Europe (limits described above); and 2) for the area of the 27 Member States of the European Union.

\section{TAXONOMIC SCOPE}

The European Red List consists of a selection of 436 saproxylic beetles species native to Europe or naturalised in Europe before AD 1500. The selection of species covers all the families or subfamilies of saproxylic beetles listed on the annexes of the EU Habitats Directive and entire families of key old growth species. Table 1 lists the families and subfamilies assessed.

The European Red List uses Fauna Europaea (www.faunaeur.org) as its default taxonomy for saproxylic beetles.

Distinct subpopulations and subspecies of saproxylic beetles within Europe were not individually assessed as part of this study.

\begin{tabular}{|c|c|c|c|c|c|c|}
\hline \multirow[t]{2}{*}{ Class } & \multirow[t]{2}{*}{ Onder } & \multirow{2}{*}{$\begin{array}{l}\text { Family } \\
\quad \text { (Subfamily) }\end{array}$} & \multicolumn{2}{|c|}{ Europe } & \multicolumn{2}{|c|}{ EU 27} \\
\hline & & & $\begin{array}{l}\text { Number of } \\
\text { species }\end{array}$ & $\begin{array}{l}\text { Number of } \\
\text { endemic species } \\
\text { ( } \% \text { endemic) }\end{array}$ & $\begin{array}{l}\text { Numbet of } \\
\text { species }\end{array}$ & $\begin{array}{l}\text { Number of } \\
\text { endemic species } \\
\text { (\% endemic) }\end{array}$ \\
\hline \multirow[t]{23}{*}{ Insecta } & \multirow[t]{23}{*}{ Coleoptera } & Anobiidac & 1 & 1 & 1 & 1 \\
\hline & & Boridae ${ }^{*}$ & 1 & 0 & 1 & 0 \\
\hline & & Bostrichidae* & 22 & $3(13.6 \%)$ & 22 & $3(13.6 \%)$ \\
\hline & & Buprestidae & 1 & 1 & 1 & 0 \\
\hline & & Cerambycidae & 153 & 32 & 138 & 17 \\
\hline & & (Cerambycinae* Prioninae $)$ & 142 & $31(21.8 \%)$ & 128 & $17(13.396)$ \\
\hline & & (Lamiinae) & 11 & 1 & 10 & 0 \\
\hline & & Cerophytidae* & 1 & 0 & 1 & 0 \\
\hline & & Cetoniidac* & 24 & $8(33.3 \%)$ & 23 & $4(17.4 \%)$ \\
\hline & & Cucujidac* & 6 & $2(33.3 \%)$ & 6 & $1(16.7 \%)$ \\
\hline & & Elateridae* & 115 & $56(48.7 \%)$ & 110 & $41(37.3 \%)$ \\
\hline & & Erotylidac* & 23 & $9(39.1 \%)$ & 23 & $4(17.4 \%)$ \\
\hline & & Euchiridac* & 2 & $1(50 \%)$ & 2 & $1(50 \%)$ \\
\hline & & Eucnemidac* & 31 & $15(48.4 \%)$ & 29 & $4(13.8 \%)$ \\
\hline & & Latridiidae & 1 & 0 & 1 & 0 \\
\hline & & Leiodidae & 1 & 1 & 1 & 0 \\
\hline & & Lucanidac* & 14 & $6(42.9 \%)$ & 14 & $4(28.6 \%)$ \\
\hline & & Melandryidae & 1 & 0 & 1 & 0 \\
\hline & & Mycetophagidac* & 15 & $2(13.3 \%)$ & 14 & 0 \\
\hline & & Prostomidac* & 1 & 0 & 1 & 0 \\
\hline & & Pythidac* & 3 & 0 & 3 & 0 \\
\hline & & Rhysodidac* & 3 & 0 & 3 & 0 \\
\hline & & Trogositidae* & 16 & $6(37.5 \%)$ & 13 & $3(23.1 \%)$ \\
\hline Total & & & 435 & 143 & 408 & 83 \\
\hline
\end{tabular}

*An asterisk indicates that the family (or subfamily) has been fully assessed. Only for these families the $\%$ of endemic species is shown.

Table 1. Diversity and endemism in selected saproxylic beetle families in Europe.

This table includes species that are native or naturalised since before AD 1500; species introduced after this date are not included. Species of marginal occurrence in Europe and/or the EU are included. For the EU 27 assessment the Not Evaluated species (species which do not occur in the EU and that represent a total of 27 species) are excluded. 


\section{METHODOLOGY}

The threatened status of all species was assessed using the IUCN Red List Categories and Criteria (IUCN 2001), which are the world's most widely accepted system for measuring extinction risk. All assessments followed the Guidelines for Application of IUCN Red List Criteria at Regional Levels (IUCN 2003).

The first step in the process in compiling this red list was to identify and establish a regional expert network of saproxylic beetles in Europe - in particular a network of 72 experts from 35 European countries were involved in the process and contributed with their knowledge and enthusiasm.

The second step was to agree on a selection of species to assess and compile the list of species.

The task of collecting the initial data was divided up geographically, by country. Experts collected information about the species per country and entered the data into the IUCN Species Information Service (SIS). For all the species, the following data were compiled:

- Species' taxonomic classification

- Geographic range (including a distribution map)

- Red List Category and Criteria

- Population information

- Habitat preferences

- Major threats

- Conservation measures (in place, and needed)

- Species utilisation

- Other general information

- Key literature references

European saproxylic beetles experts were invited to attend a five-day regional review workshop, which was held at the Hyytiala Forestry Field Station, Finland in June 2009.

Preliminary species summary reports were distributed to all the participants before the workshop to allow them to review the data presented and prepare any changes to the data. Focused working groups were organised to efficiently review identified geographical sets of species. New information was added to the species summaries and maps, and corrections to existing data were made.

Preliminary Red List Assessments for each species were then made at the European and EU 27 levels. Facilitating staff from the IUCN Red List Unit and the IUCN Regional Office for Pan-Europe reviewed the assessments to ensure they complied with the guidelines for application of the IUCN Red List Categories and Criteria and included the most up-to-date comprehensive information. Following the review workshop, the data were edited, and outstanding questions were resolved through communications with the workshop participants. The post-workshop draft assessments were also made available to allow the participating scientists to make any final edits and corrections. The resulting finalised IUCN Red List assessments are a product of scientific consensus concerning species status and are backed by relevant literature and data sources.

\section{RESULTS}

\section{Threatened status of saproxylic beetles}

The status of saproxylic beetles was assessed at two regional levels: geographical Europe (Fig. 3) and EU 27 (Fig. 4).

At the European level $10.7 \%$ were considered threatened, of which 0.5 Critically Endangered, 6.3\% Endangered and 3.9\% Vulnerable. A further $13 \%$ are considered Near Threatened.

A higher proportion of threatened species was seen in the EU 27 (14\% threatened, of which 0.7 Critically Endangered, 7.9\% Endangered and 5.4\% Vulnerable) with $14 \%$ Near Threatened. However, for more than a quarter of the species in Europe $(28 \%)$ there were not enough scientific information to evaluate their risk of extinction and they were classified as Data Deficient; when more data become available, many might well prove to be in fact threatened. 
Furthermore, five saproxylic beetle species were considered as Not Applicable, either because they were introduced after AD1500 or are of marginal occurrence in the European region.

Table 2. Summary of numbers of selected saproxylic beetle species within each category of threat.

\begin{tabular}{|c|c|c|c|}
\hline & IUCN Red List categories & $\begin{array}{l}\text { No. species Europe } \\
\text { (no. endemic species) }\end{array}$ & $\begin{array}{c}\text { No. species EU } 27 \\
\text { (no. endemic species) }\end{array}$ \\
\hline & Extinct (EX) & 0 & 0 \\
\hline & Extinct in the Wild (EW) & 0 & 0 \\
\hline & Regionally Extinct (RE) & 0 & 0 \\
\hline \multirow{3}{*}{$\begin{array}{l}\text { Threatened } \\
\text { categories }\end{array}$} & Critically Endangered (CR) & $2(2)$ & $3(2)$ \\
\hline & Endangered (EN) & $27(17)$ & $32(13)$ \\
\hline & Vulnerable (VU) & $17(10)$ & $22(9)$ \\
\hline & Near Threatened (NT) & $56(22)$ & $56(11)$ \\
\hline & Least Concern (LC) & $207(30)$ & $200(6)$ \\
\hline & Data Deficient (DD) & $122(62)$ & $94(42)$ \\
\hline & Total number of species assessed ${ }^{*}$ & $431(143)$ & $407(83)$ \\
\hline
\end{tabular}

Figure 3. Red List status of saproxylic beetles in Europe

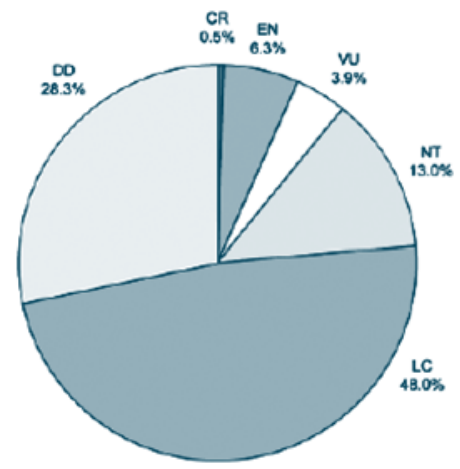

\section{Spatial distribution of species}

The intermediate latitudes (France, Germany, Slovak Republic) as well as southern Europe clearly stand out as areas of high species richness for saproxylic beetles. The Balkan Peninsula emerges as a hotspot of beetles biodiversity, highlighting the importance of the new Member States Bulgaria and Romania for biodiversity conservation in the EU.

The greatest concentration of threatened saproxylic beetles species are found in central and Eastern Europe, with the Italian Peninsula, Greece and Cyprus also highlighted as having a high number of threatened species.
Figure 4. Red List status of saproxylic beetles in the EU

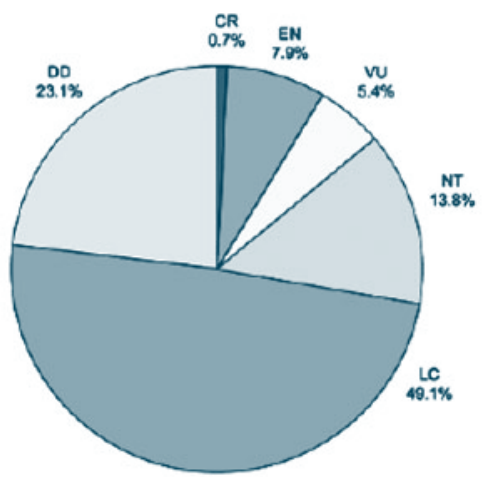

Saproxylic beetle species show particularly high endemic species richness in central and Eastern Europe. The Pyrenees and southern Europe also show an important concentration of endemism. The Mediterranean islands and Macaronesian islands have many range-restricted endemic saproxylic beetles.

\section{Major threats}

Much of Europe is a cultural landscape, having been occupied and intensively exploited by people for thousands of years (Fig. 5). The result has been that the richest areas for saproxylic beetles are no 
longer natural forests but are remnant old growth occurring in a wide variety of situations. Logging and wood harvesting have undoubtedly dramatically reduced the species-richness and abundance of saproxylic beetles in the past and almost certainly continue to do so locally, but in many parts of the continent old growth habitat persists in land which has been managed as wood pasture for many hundreds of years and is threatened more by agricultural intensification and development.

While logging and wood harvesting appear to have by far the largest impact on both threatened and non-threatened saproxylic beetles affecting 35 out of 75 threatened species and 232 species in total, agriculture expansion and intensification as well as urban sprawl are the next most important threats, impacting on 25 and 26 species, respectively. The threats for a total of 86 saproxylic species remain unknown.

Also of considerable significance is the lack of understanding and of consideration of the habitat needs of saproxylic beetles by most conservation professionals and resources managers. Saproxylic organisms depend on the dynamics of tree aging and wood decay processes, which in turn have implications for land management - non intervention or minimum intervention in former wood pasture can kill, and prevent the renewal of old trees and can therefore be very damaging; livestock grazing can also be essential to maintain adequate habitats.

A major threat in the Mediterranean zone although not unique to it - is the damage caused by fire. The burning of rough hillsides to refresh the pastures for grazing and to suppress scrub development can result in the early death of trees and suppress natural regeneration. Conversely fire suppression is a major threat to many boreal beetles, which need the burnt wood which results.

And, of course, climate change is potentially a major threat, which might exceed all of the above in its impacts on saproxylic beetles. Assessment of the potential impacts of climate change is seriously challenging and attempts at proactive conservation would be fraught with difficulty. Climate change has the potential for major impact on all of the saproxylic beetles assessed and the low rating emerging from the current assessment reflects our limited understanding and appreciation of the issues rather than the actual threat level.

The above are broad and long-term threats but there are also more short-term and localised threats arising from - often ill-informed - sanitation and forest hygiene objectives, as well as - often misconceived - safety constraints in areas well-used by people, where old trees and dead branches are often automatically removed without any serious assessment of the actual threat levels involved.

Information has not been collected during the assessment process on the relative importance of one threat compared to another for a particular species. Development of such information in the future is a priority for the assessment and will enable a more complete analysis of significant threats to species.

Figure 5. Major threats to saproxylic beetles in Europe

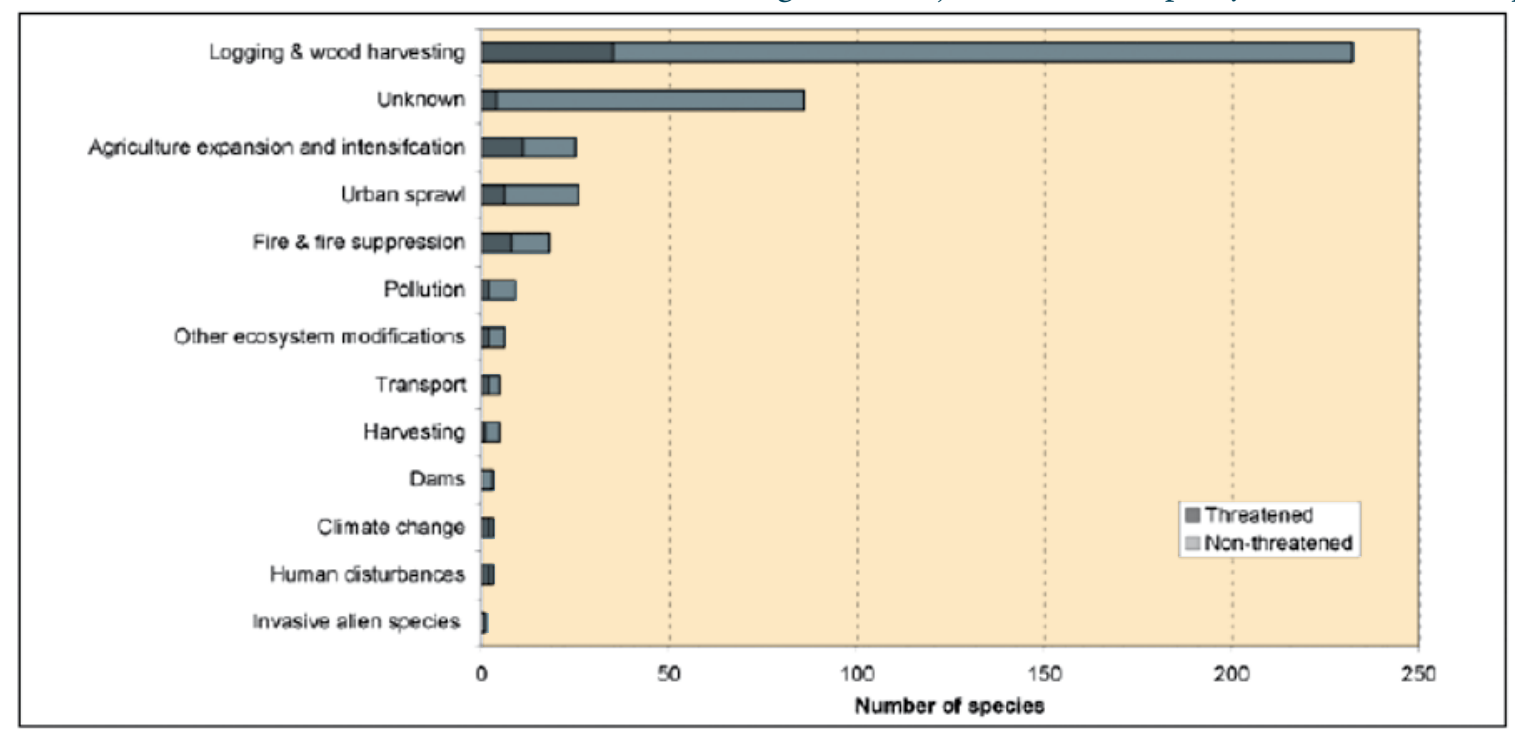




\section{Demographic trends}

Documenting population trends is one key to assessing species status and a special effort was made to determine which species are believed to be significantly declining, stable, or increasing. Nearly 14\% of the European saproxylic beetles assessed so far are considered to be declining in population. Approximately $27 \%$ are thought to be more or less stable, and only $2 \%$ appear to be increasing. However the population trend for 249 species (57\%) remains unknown (Fig. 6).

Figure 6. Population trends of European saproxylic beetles

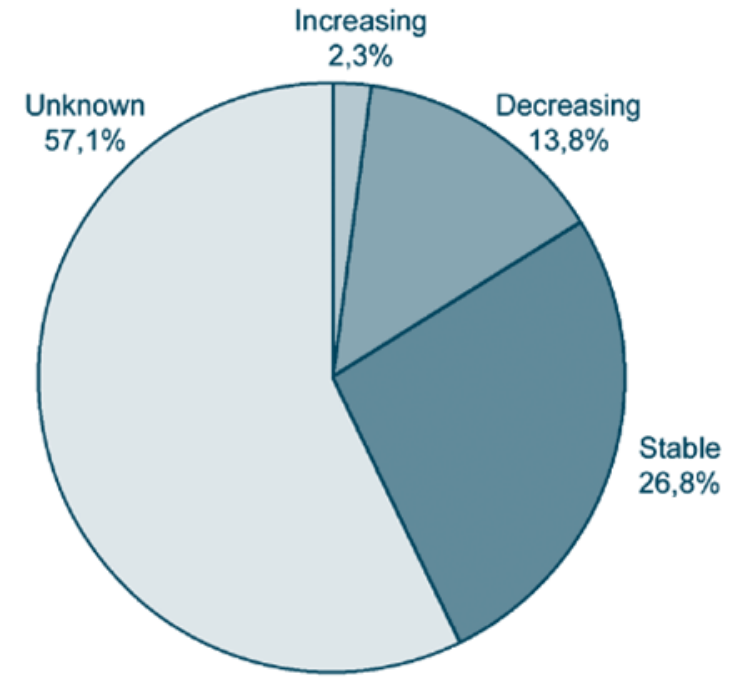

\section{CONCLUSIONS}

Through the process of compiling the European Red List of saproxylic beetles a number of knowledge gaps have been identified.

Across Europe there are significant geographic, geopolitical and taxonomic biases in the quality of data available on the distribution and status of species. It would appear that few European countries -if any- have any kind of organised and systematic monitoring for saproxylic beetle species. In most countries of the EU even basic data on the species distribution and population status are limited. While sites designated as Special Areas of Conservation for particular saproxylic beetle species do require monitoring for the six year reporting cycle it is unclear at present how much work has actually taken place.
There is a clear need for drawing together information on all initiatives under way or planned and for a wider European saproxylic beetle conservation action plan to be explored, developed and progressed.

A challenge for the future is to improve monitoring and the quality of data, so that the information and analysis presented here can be updated and improved, and conservation action can be given as solid a scientific basis as possible.

The taxonomic coverage of this Red List also requires expanding, as only a small proportion of Europe's saproxylic beetles have been assessed.

\section{ACKNOWLEDGEMENTS}

Coordination of the European Red List of saproxylic beetles was carried out by Ana Nieto (IUCN Regional Office for Pan-Europe) and Helen Temple (IUCN Species Programme). We received expert advice and assistance from Keith N.A. Alexander (IUCN Saproxylic Beetles Specialist Advisor). Guidance, advice and support were provided by IUCN staff.

The European Red List of saproxylic beetles was commissioned and funded by the European Commission. Additional support to IUCN, that contributed to the success of the workshop was provided by the Ministry of the Environment of Finland.

The European Saproxylic Beetle Assessment was entirely dependent on more than 72 experts from over 35 countries in Europe, who generously gave of their time and knowledge. We record our thanks to the following people, asking for forgiveness from anyone whose name is inadvertently omitted or misspelled:

Aleksandrowicz Oleg, Alexander Keith, Audisio Paolo, Bahillo Pablo, Baselga Andres, Bekchiev Rostislav, Bouget Christophe, Brustel Herve, Buche Boris, Buse Jorn, Campanaro Alejandro, Chobot Karel, De la Rosa Juan Jesus, Delnatte Julien, Dodelin Benoit, Doychev Danail, Gerend Raoul, 
Gueorguiev Borislav, Grosso-Silva José Manuel, Horak Jakub, Hrasovec Boris, Hyvarinen Esko, Istrate Petru, Jansson Nicklas, Jurc Maja, Katušić Luka, Kohler Frank, Legakis Anastasios, Lelo Suvad, Makris Christodoulos, Mannerkoski Ilpo, Martikainen Petri, Martin Ole, Mason Franco, Méndez Marcos, Merkl Otto, Micó Estefanía, Muller Jorg, Munteanu Natalia, Nardi Gianluca, Nitzu Eugen, Odegaard Frode, Oleksa Andrzej, Olšovsky Tomaš, Otero Carlos, Pedersen Jan, Pesic Vladimir, Petrakis Panos, Pettersson Roger, Peuhu Elina, Pil Natasa, Putchkov Alexander, Recalde Irurzun Jose-Ignacio, Rimsaite Jolanta, Schlaghamersky Jiri, Schmidl Jurgen, Smets Koen, Soares-Vieira Patricia, SprecherUebersax Eva, Stokland Jogeir, Sverdrup-Thygeson Anne, Telnov Dimitry, Tezcan Serdar, Thomsen Philip Francis, Tykarski Piotr, Verdugo Antonio, Viñolas Amador, Vitaly Alekseev, Vives Eduard, Voolma Kaljo, Vozar Agnes, Zabransky Petr.

\section{REFERENCES}

FAUNA EUROPAEA WEB SERVICE. 2004. Fauna Europaea version 1.1, Available online at http://www.faunaeur.

IUCN. 2001. IUCN Red List Categories and Criteria:Version 3.1. IUCN Species Survival Commission. IUCN, Gland, Switzerland.

IUCN. 2003. Guidelines for application of IUCN Red List Criteria at Regional Levels: Version 3.0. IUCN Species Survival Commission. IUCN, Gland, Switzerland.

IUCN. 2009. IUCN Red List of Threatened Species. www. iucnredlist.org.

NIETO, A. AND ALEXANDER, K.N.A. 2010. European Red List of Saproxylic Beetles. Luxembourg: Publications Office of the European Union. 